\title{
BIBLIOTECA ESCOLAR NO CONTEXTO DAS REFORMAS LIBERAIS DO FINAL DO SÉCULO XIX E INÍCIO DO SECULO XX: ANÁLISES A PARTIR DO CONCEITO DE REGIME DE INFORMAÇÃO
}

\author{
Debora Santos de Oliveira \\ Mestre em Ciência da Informação e Doutoranda \\ em "Knowledge Society" pela Universidad \\ de Salamanca, Espanha. \\ debora_oliveira@id.uff.br. \\ https://orcid.org/0000-0001-5084-3936
}

\author{
Elisabete Gonçalves de Souza \\ Professora do Programa de Pós-Graduação em Ciência \\ da Informação da Universidade Federal Fluminense, Brasil. \\ elisabetes.souza@gmail.com. \\ https://orcid.org/0000-0001-9707-6017
}

\section{RESUMO}

Este artigo traz dados históricos sobre a biblioteca escolar no Brasil, com destaque para sua inserção nas reformas educacionais ocorridas no país em meados dos séculos XIX e XX. Trata-se de uma pesquisa de caráter exploratória, pois estabelece o levantamento bibliográfico como caminho principal para investigação, com análises sob o ponto de vista do conceito de regime de informação. O estudo enfatiza as problemáticas relacionadas à biblioteca escolar e à educação nos anos de 1920-30, período em que a biblioteca escolar é mencionada pela primeira vez nas políticas públicas para a educação; destaca a criação do Instituto Nacional do Livro (INL) e do Instituo Nacional de Estudos e Pesquisas Educacionais Anísio Teixeira (INEP), instituições estratégicas para o fomento de políticas alinhadas com projeto urbano-industrial em curso. Conclui que o novo regime de informação, conduzido pelo governo Vargas, espraiou-se pelo campo educacional com o apoio dos escolanovistas, ressignificando as funções da escola e de sua biblioteca.

Palavras-chave: História da biblioteca escolar no Brasil. Educação e biblioteca no Brasil. Escola Nova. Regime de informação.

\section{SCHOOL LIBRARY IN THE CONTEXT OF LIBERAL REFORMS OF THE END OF THE 19TH CENTURY AND EARLY 20TH CENTURY: ANALYSIS FROM THE INFORMATION REGIME CONCEPT}

\section{ABSTRACT}

This article presents historical data about the school library in Brazil, with emphasis on its inclusion in the educational reforms that took place in the country in the middle of the 19th and 20th centuries. This is an exploratory research, as it establishes the bibliographic survey as the main path for investigation, with analysis from the point of view of the concept of information regime. The study emphasizes the issues related to the school library and education in the 1920s and $30 \mathrm{~s}$, a period when the school library is mentioned for the first time in public education policies. The study also highlights the creation of the National Book Institute (INL) and the National Institute of Educational Studies and Research Anísio Teixeira (INEP) strategic institutions for the promotion of policies aligned with the ongoing urban-industrial project. It concludes that the new information regime, conducted by the Vargas government, spread across the educational field with the support of the escolanovistas, giving new meaning to the functions of the school and its library.

Keywords: History of the school library in Brazil. Education and library in Brazil. Escola Nova. Information regime.

Recebido em: 30/09/2020

Aceito em: 04/02/2021

Publicado em: 12/07/2021

\section{INTRODUÇÃO}

O campo informacional da biblioteca escolar se materializa nos aspectos significativos que compõem o ambiente chamado escola. Oliveira (2019, p.14) define esse processo dizendo que: "[...] há muitas relações transversais que tocam a biblioteca escolar como, por exemplo, os alunos, os usuários, os bibliotecários, os professores, os livros, o projeto 
político-pedagógico". Este espaço discursivo, formado pela escola e sua biblioteca, quando analisado pelas perspectivas das configurações da sociedade, do Estado e do mercado tem matizes diferentes que se coadunam com as intencionalidades do regime de Informação em curso, como ocorreu no Brasil nos anos de 1880-1890 do século XIX, período em que o projeto de modernização de corte liberal-manufatureiro começava a despontar em crítica ao modelo agrário-exportador dominante.

É no quadro das reformas liberais que o presente artigo procura analisar o percurso histórico da biblioteca escolar no Brasil, entre o final do século XIX e o início do século XX, mais especificamente os anos de 1930, quando a burguesia industrial lança suas teses com vista a modernizar o Estado e a reformulá-lo para poder dirigi-lo, instaurando um novo de regime de Informação. Segundo González de Gómez (2008; 2012), o conceito de regime de informação é um instrumento analítico que nos permite reconstruir os "[...] modos de produção de ações e práticas de informação, ancoradas nas redes densas de relações culturais, sociais e econômicas e condicionadas pelas estruturações preferenciais das relações de poder" (GONZÁLEZ DE GÓMEZ, 2008, p.2).

Abordar a biblioteca escolar sob o enfoque do conceito de regime de informação, como plano de análise, permite-nos observar o campo transversal em que ela se aloja a partir das possíveis relações e interações informacionais que perpassam a esfera da escola no Brasil, seus atores, normas e instituições. $\mathrm{Na}$ área educacional, destaca-se a influência do movimento escolanovista, cujo Primeiro Manifesto (1932) apontava, ainda que de forma não sistematizada, a preocupação com equipamentos educacionais para 0 desenvolvimento da aprendizagem, como laboratórios e bibliotecas, tendo em vista o desenvolvimento de um projeto de nação nos quadros da modernidade capitalista, em que escola torna-se um lugar fundamental para o desenvolvimento das forças produtivas.

O ideário do movimento escolanovista se coadunava com 0 projeto nacional-desenvolvimentista liderado pela burguesia nacional, que, para se afastar das disputas políticas, colocava-se envolta no manto da racionalização administrativa, cujas ações envolviam a gestão da informação para tomada de decisões. Ações essas consubstanciadas por meio da criação de órgãos assessores em diversas áreas, como Instituto Nacional do Livro (INL) ${ }^{1}$ e o Instituto Nacional de Estudos e Pesquisas

\footnotetext{
1 O INL foi o órgão responsável pela política nacional do livro e das bibliotecas por sessenta anos. Tinha como uma de suas finalidades incentivar a criação de bibliotecas públicas no Brasil. O órgão foi extinto em 1992, substituído pelo SNBP (Sistema Nacional de Bibliotecas Públicas).
} 
Educacionais Anísio Teixeira (INEP) ${ }^{2}$, agências que direta e indiretamente tiveram e têm relação com a questão do livro e das bibliotecas públicas e escolares.

Sendo assim, por meio de revisão de literatura, buscou-se abordar, sob a lente do conceito de regime de informação, a história das bibliotecas escolares, concentrando-se nestes períodos da história da educação no Brasil: o final do Segundo Reinado e as reformas educacionais oitocentistas; a crise da República Velha e a ascensão do governo Vargas e sua aproximação com o ideário escolanovista, cujas declarações sociais sobre 0 papel da educação no projeto de modernidade convocaram a biblioteca escolar a integrar o cenário educacional.

\section{EDUCACÃO NO BRASIL NO FINAL DO SÉCULO XIX E INÍCIO DO SÉCULO XX}

No início do século XIX, a educação brasileira ainda respirava os resquícios da educação religiosa de corte propedêutico, cujas práticas educativas forjavam uma educação elementar voltada para a alfabetização das classes subalternas, por meio da ação do professor régio, e uma educação secundária e superior direcionada às classes dominantes.

Apesar de o Brasil ter alcançado sua emancipação política em 1822, sua organização econômica continuava dependente das relações comerciais com a Europa, com países como França, Inglaterra e a ex-metrópole Portugal. A base econômica agrário-exportadora não via a escolarização como uma prioridade para o desenvolvimento das forças produtivas. Isso levou o governo Imperial a abrir mão de investir na educação elementar em todo o território, passando essa função para as Províncias, por meio do Ato Adicional de 1834, cabendo a elas organizar a educação pública (ROMANELLI, 2012). As províncias mais ricas desenvolveram uma rede de ensino, como ocorreu em São Paulo, outras, no entanto, sem recursos financeiros, pouco ou nada fizeram para ampliar suas escolas.

[...] reforma constitucional de 12/8/1834, que, atendendo ao movimento descentralista, conferiu às Assembléias Legislativas Provinciais, então criadas, entre outras atribuições, a de legislar "sobre a instrução pública e estabelecimentos próprios a promovê-la" (art.10, item 2), com exclusão das escolas superiores então já existentes e de outros estabelecimentos de qualquer tipo ou nível [...] (TANURI, 2000, p.63).

2 O INEP, durante a sua história, recebeu várias denominações, mas mantendo sempre a sigla original: Instituto Nacional de Pedagogia (1937), Instituto Nacional de Estudos Pedagógicos (1938), Instituto Nacional de Estudos e Pesquisas Educacionais (1972) e, em 2003, Instituto Nacional de Estudos e Pesquisas Educacionais Anísio Teixeira. 
Entre 1848 e 1871, por influência da revolução francesa, as demandas sociais passaram a ser pauta de setores progressistas da sociedade e, dentre suas exigências, surgiu a necessidade de se ampliar o ensino elementar. No entanto, só no final do século XIX, em 30 de junho de 1880, é que nasce, nas dependências da Escola Normal Caetano de Campos, em São Paulo, a primeira biblioteca escolar.

A criação de bibliotecas escolares, no sentido hoje entendido, começou a acontecer no país com a fundação das escolas normais. A primeira a ser criada foi a Biblioteca da Escola Normal Caetano de Campos, São Paulo, em 30 de junho de 1880 e, anos depois, em 16 de junho de 1894, inaugura-se a Biblioteca do Ginásio do Estado da Capital [...] (VALIO, 1990, p.18).

Conforme relata Tanuri (2000), nas décadas de 70 e 80 do século XIX, tivemos uma intensa movimentação de ideias no campo político, econômico e ideológico com profundas repercussões no setor educacional, que passava a ter uma importância até então não vislumbrada, passando "[...] a difusão do ensino ou das 'luzes', como se dizia, a ser encarada como indispensável ao desenvolvimento social e econômico da nação [...]" (TANURI, 2000, p.66).

Essa nova ideologia objetivava unir o trabalho à educação, em troca da formação do cidadão-eleitor. Políticos, como Rui Barbosa, enfatizavam que a sociedade brasileira deveria iniciar e desenvolver a cultura do voto, fato que nos diferenciaria como um povo livre. As reformas educacionais postuladas por Rui Barbosa possuíam o caráter de ensinar o homem a votar. Machado (2011) corrobora dizendo que "[...] a discussão sobre a necessidade de investimento na educação estava relaciona à importância da formação do cidadão-eleitor" (MACHADO, 2011, p.93).

Ou seja, o novo "regime de informação" fazia solicitações à escola com o intuito de unir a educação com o novo pensamento político-econômico do final do Império, cujos traços liberais se punham em choque com o pensamento conservador das oligarquias agro-exportadoras. Essa tendência se expressa nas reformas educacionais de então, por meio das quais os liberais tentaram se desvencilhar do passado escravocrata, realçando o tempo presente como manifestação da modernidade. Desprezavam-se as ações do "antigo regime" e propagavam novas práticas de ensino, entre elas, aquelas que incluíam a difusão do livro e da biblioteca.

[...] a difusão de novos métodos de ensino simultâneo, intuitivo (as lições de coisas) e de alfabetização (os métodos analíticos, que buscavam 
conciliar o ensino da leitura e da escrita); a propagação das bibliotecas escolares e a criação do Museu Pedagógico (1883); [...] a transformação da cultura material da escola primária (mobiliários, livros, textos, mapas e globos, lousas e ardósias individuais, caixas econômicas escolares etc.); a efervescência do mercado editorial de livros didáticos; [...] (SCHUELER; MAGALDI, 2009, p.37).

A instauração da República, em 1889, fez aflorar um projeto de nação que procurou negar suas raízes agrárias e escravistas, contraditoriamente perpetuada pelas oligarquias regionais. Nesse contexto, um novo ator começa a despontar: a escola pública enquanto valor universal, face à necessidade da formação para o trabalho urbano-industrial; a necessidade de alfabetizar o eleitor, visando retirar das oligarquias agrárias o controle dos estados. Uma nova rede de informação estruturava-se em vista dos novos contornos sociopolíticos e econômicos em curso.

\subsection{Escola e biblioteca: as reformas liberais na educação}

Para a biblioteca escolar brasileira, o século XX foi muito promissor. Nesse momento, ela se distingue como participante do movimento político pedagógico e aproxima-se do conceito de "recurso pedagógico" tal como a conhecemos hoje. Eggert-Steindel e Fonseca (2010) apontam que as primeiras décadas desse século foram cruciais para o desenvolvimento da biblioteca escolar e destacam alguns agentes que foram importantes para tirar a biblioteca da penumbra e inseri-la no contexto das políticas pedagógicas, como o movimento da Escola Nova.

[...] um movimento de educadores europeus e norte-americanos, organizado em fins do século XIX, que propunha uma nova compreensão das necessidades da infância e questionava a passividade na qual a criança estava condenada pela escola tradicional. Também conhecida como Educação Nova, a Escola Nova tem seus fundamentos ligados aos avanços científicos da Biologia e da Psicologia. Pode-se afirmar que, em termos gerais, é uma proposta que visa a renovação da mentalidade dos educadores e das práticas pedagógicas (MENEZES; SANTOS, 2001, p.1).

No Brasil, o movimento fortaleceu-se após a criação da Associação Brasileira de Educação, em 1924, mas se radicalizou nos meandros da IV Conferência Nacional de Educação de 1931, que dividiu os grupos que defendiam a educação em católicos e liberais. O movimento contou com a adesão de intelectuais como Anísio Teixeira, Fernando de Azevedo e Lourenço Filho, conhecidos como "os reformadores", "os pioneiros da educação nova" e principais signatários de um documento que impactou a história da educação no Brasil: o Manifesto dos Pioneiros da Educação (1932). 
O Manifesto incluía propostas educacionais renovadoras e defendia a secularização da educação, colocando-a como um dever do Estado e direito de todo cidadão.

Um ponto importante dessa secularização para a qual trabalharam incansavelmente foi operar a passagem da escola enquanto extensão do campo familiar, privado e religioso para o espaço público da cidade. Os sinais de que a lgreja, no início do século $X X$, comandava o campo educacional, detendo o monopólio educativo, são bem concretos e podem ser notados no conteúdo das cartilhas, nos livros de leitura, nos programas escolares, na forma como os alunos tratavam os mestres [...] (NUNES, 1998, p.109).

O documento propagava um diálogo entre a educação e os desafios urbanos e industriais. "No Brasil, a Escola Nova buscava a modernização, a democratização, a industrialização e urbanização da sociedade" (MENEZES; SANTOS 2001, p.1). Isso ocorreu porque o desenvolvimento do projeto industrialista colocou outras exigências educacionais, visando garantir a "[...] produção e reprodução de mão-de-obra mais qualificada, o que acarretou ampliação das matrículas escolares e a elevação do nível educacional das populações urbanas [...]" (LEMOS, 2008, p.106).

Nesse contexto, a institucionalização da biblioteca escolar, como instrumento de estímulo ao aprendizado e à leitura, surge como uma necessidade inexorável, passando a ser vista como um recurso a auxiliar no processo de educação formal (CAMPELLO, 2008). Para os seus idealizadores "[...] ensino e biblioteca não se excluem, completam-se. Uma escola sem biblioteca é instrumento imperfeito" (LOURENÇO FILHO, 1946, p.4).

Segundo Oliveira (2019), o discurso dos escolanovistas reforçou uma postura educacional que já se punha em curso nas reformas oitocentistas, realizadas para consolidar os grupos escolares como modelo de escola. Nessas reformas, já se previam a criação de bibliotecas, mas restringiam-nas à instrução dos professores, vindo apenas a ser citadas como "[...] ambiente integrante nos grupos escolares depois da década de 1920" (MARTINS; REIS, 2016, p.205), com a radicalização do debate promovido pelos reformadores da educação nova. No quadro abaixo (QUADRO 1), fizemos uma síntese das principais reformas no ensino ocorridas em 1920 e que antecederam a divulgação do Manifesto dos Pioneiros de 1932. 
QUADRO 1 - Reformas no Ensino (1920-1930)

\begin{tabular}{|l|l|l|}
\hline REFORMAS & \multicolumn{1}{|c|}{ EDUCADORES } & \multicolumn{1}{c|}{ ESTADOS } \\
\hline 1920 & Sampaio Dória & São Paulo \\
\hline $1922-1923$ & Lourenço Filho & Ceará \\
\hline 1925 & José Augusto Bezerra de Menezes & Rio Grande do Norte \\
\hline $1927-1928$ & Lisímaco Costa & Paraná \\
\hline $1927-1928$ & Francisco Campos & Minas Gerais \\
\hline $1927-1930$ & Fernando de Azevedo & Rio de Janeiro/Distrito Federal \\
\hline
\end{tabular}

Fonte: Centro de Pesquisa e Documentação de História Contemporânea do Brasil (2018) (adequação das autoras).

Desse modo, apesar de reconhecermos a importância das reformas educacionais, ao pensarmos no movimento da Escola Nova na perspectiva dos regimes de informação, não podemos deixar de mencionar um documento central que, no plano ideológico, vai dar o tom desse debate: o Manifesto dos Pioneiros de 1932, também conhecido como Manifesto da Escola Nova.

O Manifesto é considerado um documento basilar para entendermos a inclusão da biblioteca escolar nos fluxos de informação do novo regime inaugurado com a ascensão de Getulio Vargas ao poder, cujo projeto político envolvia mudanças não só no modo de produção, mas nos modos de pensar, educar e governar. No campo da educação, dentre muitos pontos apresentados no Manifesto, no Artigo VIII, observa-se:

VIII - Desenvolvimento das instituições de educação e de assistência física e psíquica à criança na idade pré-escolar (creches, escolas, maternais e jardins de infância) e de todas as instituições complementares pré-escolares e pós-escolares. [...] Em meio a um dos princípios gerais do Manifesto, consta: d) e para a intensificação e extensão da obra de educação e cultura (bibliotecas escolares) fixas ou circulantes (museus escolares, rádio e cinema educativo) (MANISFESTO... 1932 apud AZEVEDO, 1932, p.124-125, destaque das autoras).

Nota-se que a biblioteca escolar (fixa ou circulante) é apresentada como parte da política educacional, sendo defendida pelos signatários do Manifesto como uma das instituições complementares para o desenvolvimento da educação, "na pré-escola e na pós-escola" (MANIFESTO... 1932 apud AZEVEDO, 1932 p. 124).

De acordo com González de Gómez (2002), o regime de informação deve ser lido diante de uma determinada formação social que passa, então, a determinar uma nova configuração para o modo de produção informacional. O Manifesto (1932) foi um ato inaugural, por meio do qual o planejamento do sistema educacional do país foi apreendido como nacional. Duarte e Santos (2017, p.7) destacam que o Manifesto era "[...] o documento [que] propugna pelo acesso do povo à educação escolar, mediante a extensão dos sistemas de escolas ao longo do território". 
Mas, o movimento escolanovista não contribuiu apenas com a ampliação e reforma da rede pública de escolas, ele também contribuiu para a instauração de um novo modelo de sociedade que, mesmo não podendo abrir mão de sua estrutura oligárquica, buscou abraçar um projeto industrialista. Nesse cenário, esta nova concepção de escola deveria valorizar a teoria e a prática "[...] como uma tentativa de superação da escola tradicional excessivamente rígida, magistrocêntrica e preocupada com a memorização dos conteúdos" (ARRUDA, 1989, p.204).

Diferente das reformas oitocentistas, que tinham como objetivo a alfabetização com vista a ampliar o número de eleitores, fragilizando o poder das oligarquias regionais, o projeto liberal de educação levado a cabo pelos escolanovistas centrava-se no fortalecimento da economia urbano-industrial, procurando se afastar dos atritos com as oligarquias ainda hegemônicas, reforçando, de um lado, a crítica às escolas tradicionais propedêuticas; de outro, exaltando o conhecimento técnico e sua contribuição para o desenvolvimento econômico.

A técnica moderna proporciona, com a produção humana, a todos os homens o conhecimento da natureza, o conhecimento técnico. [...] Os dualismos existentes entre educação social e humanística, antiga e moderna, teoria e prática, estão completamente superados. Não existe ensino prático sem teoria e nem ensino teórico sem a prática, pois formar técnicos sem prática seria formar homens que não sabem coisa nenhuma [...]. (TEIXEIRA, 1954, p.1196).

Conforme relata Souza (2012), nas décadas de 1930-40, boa parte da mão de obra que integrava os quadros crescentes da indústria e do comércio era de migrantes das regiões rurais. Os setores empresariais perceberam que, para integrá-los à disciplina do trabalho fabril, era necessário não apenas treiná-los para as tarefas da fábrica e do comércio, mas educá-los em relação ao espaço e tempos urbanos. Por isso, reler o Manifesto dos Pioneiros (1932), sua preocupação com a dinâmica da escola, sua didática, seus equipamentos educacionais, como laboratórios e bibliotecas, implica entendê-lo como uma peça política de um novo regime de informação. Seu texto tinha o propósito explícito de orientar as políticas educativas do recém-criado Ministério da Educação e Saúde. Porém, mais do que uma carta de intenções, o Manifesto proclamava e indicava para o governo a necessidade de uma escola renovada, alinhada como os princípios da ciência e da técnica.

Ao lado da escola pública, a biblioteca escolar, entendida como equipamento pedagógico complementar, associava-se a outras agências que despontavam 
para consolidar o novo regime de informação instaurado sob a égide do governo Vargas, como o Instituto Nacional do Livro (INL) e o Instituto Nacional de Pesquisas Pedagógicas (INEP).

\subsection{O INL e o INEP: Educação, Biblioteca e Regime de Informação.}

O INL foi criado em dezembro de 1937 pelo decreto 93 e entre suas competências estavam: a) organizar e publicar a Enciclopédia Brasileira e o Dicionário da Língua Nacional, revendo-Ihes as sucessivas edições; b) editar toda sorte de obras raras ou preciosas, que sejam de grande interesse para a cultura nacional; c) promover as medidas necessárias para aumentar, melhorar e baratear a edição de livros no país, bem como para facilitar a importação de livros estrangeiros; d) incentivar a organização e auxiliar a manutenção de bibliotecas públicas em todo o território nacional (BRASIL, 1937).

Mário de Andrade envolveu-se com o INL, no projeto da enciclopédia nacional, e defendia as bibliotecas públicas como uma das instituições mais importantes para o desenvolvimento da cultura nacional. Com esse intento, o INL comprou e distribuiu livros para várias bibliotecas públicas, contribuindo para a sua expansão. Segundo Tavares (2014), o INL contribuiu direta e eficientemente para o desenvolvimento cultural do país. "[Dentre suas ações estava] a edição de livros, bem como facilitar a sua importação e incentivar a organização e manutenção de bibliotecas públicas em todo território nacional" (TAVARES, 2014, p.165). Segundo Gugliotta (2019), o INL não apenas se preocupou com a criação de bibliotecas públicas como organizou campanhas para o cadastramento das bibliotecas existentes, assim como ofereceu assistência técnica especializada aos seus profissionais. Mas, todo esse esforço em torno do livro, primeiro, e de forma colateral em direção às bibliotecas, não foi suficiente para desencadear alguma política a ser desenvolvida especificamente para essas bibliotecas, sejam elas públicas ou as escolares, conforme nos chama a atenção Leitão (2010) e Oliveira (2019).

Segundo Gugliotta (2019), os projetos pensados no INL em torno da valorização do livro e da leitura, "[...] serviram para demonstrar que o Brasil avançava em um regime voltado para futuras políticas informacionais". Nesse cenário, as bibliotecas públicas receberam uma atenção especial em detrimento das escolares, sendo inclusive direcionadas "[...] para atuarem como complemento ao processo educacional da população brasileira". Segundo o autor, "[...] o INL cumpriu sua função, tendo em vista 
que em 1938 foram identificadas 78 bibliotecas em todo o país e em 1945 esse número havia subido para 332" (GUGLIOTTA, 2019, p.41-43).

Idealizado em 1936, mas somente regulamentado em 1938, o INEP tinha como competência a) organizar documentação relativa à história e ao estudo das doutrinas e das técnicas pedagógicas, bem como das diferentes espécies de instituições educativas; b) manter intercâmbio, em matéria de pedagogia, com as instituições educacionais do país e do estrangeiro; c) promover inquéritos e pesquisas sobre todos os problemas atinentes à organização do ensino, bem como sobre os vários métodos e processos pedagógicos; d) promover investigações no terreno da psicologia aplicada à educação, bem como relativamente ao problema da orientação e seleção profissional; e) prestar assistência técnica aos serviços estaduais, municipais e particulares de educação, ministrando-Ihes, mediante consulta ou independentemente desta, esclarecimentos e soluções sobre os problemas pedagógicos; f) divulgar, pelos diferentes processos de difusão, os conhecimentos relativos à teoria e à prática pedagógicas (BRASIL, 1938).

O INEP era o "centro de cálculo"3 dos serviços informacionais na área de educação, mantendo uma biblioteca e um museu voltados para as questões pedagógicas. Além disso, o INEP configurava-se como um órgão produtor de documentação para a difusão das ideais escolanovistas, além de manter um constante intercâmbio com os outros órgãos, dentre esses o Departamento Administrativo do Serviço Público (DASP). Essa relação aparece expressa no Art.3 do decreto que consagrou sua criação.

Constituirá ainda função do Instituto Nacional de Estudos Pedagógicos cooperar com o Departamento Administrativo do Serviço Público [DASP], por meio de estudos ou quaisquer providências executivas, nos trabalhos atinentes à seleção, aperfeiçoamento, especialização e readaptação de funcionalismo público da União (BRASIL, 1938).

Para Lourenço Filho (1946), o DASP seria o órgão executivo por excelência e o Instituto, "[...] fonte primária de documentação e investigação, com atividades de intercâmbio geral e assistência técnica" (LOURENÇO FILHO, 1946, p.10). Para Rothen (2005), Lourenço Filho vinculou as atividades do INEP com as do DASP para conseguir a sua instalação, já que, em 1936, houve uma tentativa frustrada de criação da entidade

${ }^{3}$ Latour (2000) define um centro de cálculo como uma instituição central com recursos para reunir e processar inscrições diversas vindas das periferias. Neste centro, as inscrições passam a ser padronizadas e comparadas. Após esse trabalho, essas inscrições se ampliam e transformam-se em conhecimento sobre a realidade sendo capazes de operarem modificações na própria realidade. De todas as informações geradas pelo INEP, a informação estatística se colocava no cenário político como aquela que dava legitimidade e credibilidade às ações por ser entendida como um discurso científico, imparcial, neutro. 
por parte desse educador. O autor também acentua que, Lourenço Filho tinha formação em psicologia e que já havia criado em São Paulo um serviço de Psicologia Aplicada. Essa influência aparece explicitamente nas letras "c" e "d" do Decreto (BRASIL, 1938) por meio dos termos "pesquisas" e "investigações"; sendo as pesquisas referentes a problemas educacionais e as investigações referentes aos estudos de psicologia aplicada à educação (ROTHEN, 2005).

Em síntese: além de proporem a laicidade do ensino e a ampliação da escola elementar como um direito subjetivo, o projeto escolanovista se espraiou, alimentando e se retroalimentando do projeto nacional-desenvolvimentista conduzido por Vargas. Na tarefa de auxiliar o Estado na promoção do livro e da educação no Brasil apoiou e incentivou a criação do INL e do INEP, estimulando essas instituições a promoverem ações e acumularem informação sobre os mais diversos aspectos do meio cultural e educacional, assim como, no caso do INL, auxiliar na edição e distribuição de livros e implantação de bibliotecas; no caso do INEP a produção de dados estatísticos sobre a situação das escolas, com vista à implementação de políticas públicas, recolhimento de informação sobre métodos e procedimentos didáticos (FERREIRA, 2006; GUGLIOTTA, 2019).

A ação dessas instituições "serve-nos como mais uma prova de que a informação ganhava uma nova conotação durante a Era Vargas, especificamente durante o Estado Novo" (GUGLIOTTA, 2019, p.44), tornando-se um valioso instrumento nas mãos dos intelectuais escolanovistas, políticos e gestores da administração pública.

As reformas de corte liberal, no campo político-educacional, iniciadas no final do século XIX e consolidadas no século XX, e seu discurso em prol de um Brasil moderno e industrial revelam-nos, sob as lentes de regime de informação, que houve um fortalecimento na educação nacional, favorecendo a biblioteca escolar como equipamento fundamental para o desenvolvimento da aprendizagem, ainda que de forma pragmática, como nos revela a fala de Lourenço Filho em seus escritos sobe a biblioteca escolar, sendo sua função descrita como "[...] estimular, coordenar e organizar a leitura [...], orientar os leitores, sugerir-lhes trabalhos, proporcionar-Ihes melhores recursos de organização" (LOURENÇO FILHO, 1946, 4). Nota-se que sua inserção no sistema de ensino é evidenciada como um recurso ou "equipamento" pedagógico, e não como uma instituição social e cultural.

Oliveira (2019), em estudo recente sobre a universalização da biblioteca escolar no Brasil, em que analisou a produção bibliográfica de pesquisadores e bibliotecários 
em dois fóruns da área, o Encontro Nacional de Pesquisadores em Ciência da Informação (ENANCIB) e o Congresso Brasileiro de Biblioteconomia e Documentação (CBBD), observou que aqueles que simpatizam com causa, quando tratam da questão, raramente pensam a biblioteca escolar como uma instituição social, mas como um lugar; como se a biblioteca escolar fosse apenas espaço, lugar onde são realizados serviços biblioteconômicos, atividades de leitura, ações com vista ao letramento informacional etc. Para a autora, isso nos mostra "[...] que a biblioteca escolar como instituição social, como um direito fundamental, seu desenvolvimento e sua inserção nos estudos sobre os fluxos informacionais e redes de informação ainda carece de estudos" (OLIVEIRA, 2019, p.119). Abordagens essas que procuramos retomar, contextualizando o desenvolvimento da biblioteca escolar nos dois períodos aqui estudados.

\section{CONSIDERAÇÕES FINAIS}

Como destaca González de Gómez (2002), o regime de informação é uma ferramenta teórica capaz de identificar fenômenos sociais em ascensão - como a escola pública e laica - possibilitando aproximá-los e relacioná-los com as questões informacionais que direta ou indiretamente os envolvem.

A proposta deste artigo foi fomentar ideias na direção de conhecer os contextos que cercaram a institucionalização da biblioteca escolar em dois períodos da história da educação no Brasil: o final do século XIX e o início do século XX, com destaque para os anos de 1930 e o movimento dos liberais da educação nova, procurando identificar as intencionalidades dos discursos liberais que se punham em cena, relacionando-os com os projetos de poder em disputa pelas classes dominantes, cujas ações de governança, a partir da década de 30, exigiram a instauração de um novo regime de informação que tinha a educação como variável política e econômica para o desenvolvimento urbano-industrial.

O projeto de modernização do Estado sob a direção de Vargas (1930-1945) resultou em mudanças na sua estrutura administrativa, assim como em transformações burocrático-administrativas no âmbito governamental, para atender às demandas de desenvolvimento científico e tecnológico impostas pela industrialização. É nesse contexto que a noção de universalização da escola surge com vista a estabelecer requisitos mínimos educacionais, como a obrigatoriedade da educação primária para todos os cidadãos. 
Sem minimizar o impacto das reformas educacionais que passaram a associar, de forma efetiva, a escola e a biblioteca, destacamos o Manifesto dos Pioneiros de 1932, como o documento norteador de um novo regime de informação para o campo da educação, no sentido de incluir a escola em um projeto de Estado, com foco nas ações econômicas (formação de mão de obra) e políticas: novas formas de governança, já que a alfabetização ampliaria o número de eleitores.

Dentro dos limites da discussão proposta neste artigo, pode-se dizer que o discurso escolanovista ressignificou a representação da biblioteca, trazendo-a para o centro da escola, ainda que a entendesse como um recurso complementar ao ensino-aprendizagem e não como uma instituição social, educativa e cultural, cuja ação não se restringe ao apoio ao curricular. $O$ tom desse discurso pode ser identificado na narrativa pragmática sobre a biblioteca como lugar para "[...] treinar as crianças em atividades sociais (clubes de leitura e dramatização, autocontrole dos alunos etc.) [...]" (MEIRELES, 1979 apud MARTINS; REIS, 2016, p.236). Um discurso com forte influência daquilo que os educadores liberais chamavam de "racionalidade técnica", que atingia a escola e seus equipamentos, como a biblioteca escolar.

Em um contexto como os anos de 1930 em que a modernização do Estado é definida por sua racionalidade técnica, o INL e INEP, como vimos, atuavam como agências a fim de produzir informações para um novo sistema sócio-político-econômico que se punha em cena, para o qual a informação tornar-se-ia um item fundamental para a tomada de decisões com vista à criação e à manutenção de um sistema público de ensino alinhado com os objetivos de um novo projeto de Nação, que tinha a industrialização e a racionalização da gestão pública como um projeto de Estado.

\section{REFERÊNCIAS}

ARRUDA, Maria Aparecida (org.). História da educação. Belo Horizonte: Autêntica, 1989.

AZEVEDO, Fernando. A Reconstrução educacional no Brasil: ao povo e ao governo. Manifesto dos pioneiros da educação nova. São Paulo: Nacional, 1932. Disponível em:

http://www.dominiopublico.gov.br/download/texto/me4707.pdf Acesso em: 10 de jun. de 2020.

BRASIL. Decreto-lei n̊93, de 21 de dezembro de 1937. Cria o Instituto Nacional do Livro [texto on line]. Disponível em: https://www2.camara.leg.br/legin/fed/declei/1930-1939/decreto-lei-93-21dezembro-1937-350842-publicacaooriginal-1-pe.html Acesso em: 10 de jun. 2020.

BRASIL. Decreto-lei ํo580, de 30 de julho de 1938. Dispõe sobre a organização do Instituto Nacional de Estudos Pedagógicos [texto on line]. Disponível em:

http://download.inep.gov.br/acesso_a_informacao/base_juridica/decreto_lei_n580_30071938_instala cao_inep.pdf/Acesso em 10 de jun. 2020. 
CENTRO DE PESQUISA E DOCUMENTAÇÃO DE HISTÓRIA CONTEMPORÂNEA DO BRASIL. Anos 20: questão social e reformas educacionais. Rio de Janeiro: CPDOC/FGV, 2018. Disponível em: https://cpdoc.fgv.br/producao/dossies/AEraVargas1/anos20/QuestaoSocial/ReformasEducacionais Acesso em: 3 de abril 2019.

DUARTE, Marisa R. Teixeira; SANTOS, Maria Rosimary S. dos. Sistema Nacional de Educação e Planejamento no Brasil. Rev. Bras. Educ., Rio de Janeiro, v.22, n.71, 2017. Disponível em: http://www.scielo.br/scielo.php?script=sci_arttext\&pid=S1413$24782017000400225 \&$ Ing=en\&nrm=iso Acesso em 29 de jun. 2020.

EGGERT-STEINDEL, Gisela e FONSECA, Caio Faria. A biblioteca escolar: participante da promoção da justiça e êxito escolar. In: VALLE, Ione Ribeiro; SILVA, Vera Lucia Gaspar da; DAROS, Maria das Dores Daros (org.). Florianópolis: Ed. UFSC, 2010.

FERREIRA, Márcia dos Santos. Centros de Pesquisas do INEP: pesquisa e política educacional entre as décadas de 1950 e 1970. 2006. 315f. Tese (Doutorado em Educação) - Faculdade de Educação, Universidade de São Paulo. São Paulo, 2006.

GONZÁLEZ DE GÓMEZ, Maria Nélida. Novos cenários políticos para a informação. Ciência e Informação, Brasília, v.31, n.1, p.27-40, jan./abr. 2002. Disponível em http://www.scielo.br/pdf/ci/v31n1/a04v31n1.pdf Acesso em 09 de set. 2020.

GONZÁLEZ DE GÓMEZ, Maria Nélida; CHICANEL, Marize. As mudanças de regimes de informação e as variações tecnológicas. In: ENCONTRO NACIONAL DE PESQUISA EM CIÊNCIA DA INFORMAÇÃO, 9., 2008, São Paulo. Anais... São Paulo: USP, 2008.

GONZÁLEZ DE GÓMEZ, Maria Nélida. Regime de Informação: construção de um conceito. Inf. \& Soc.: Est., João Pessoa, v.22, n.3, p.4360, set./dez.2012.

GUGLIOTTA, A. Da informação técnico-administrativa à científico-tecnológica: a influência do regime de informação estadocêntrico na formação do Instituto Brasileiro de Bibliografia e Documentação (IBBD). Niterói, 2019. Tese (Doutorado em Ciência da Informação) - Universidade Federal Fluminense, Niterói, 2019.

LATOUR, Bruno. Redes que a razão desconhece: laboratórios, bibliotecas, coleções.

In: BARATIN, Marc; JACOB, Christian (org). O poder das bibliotecas: a memória dos livros no ocidente. Rio de Janeiro: UFRJ, 2000. p.21-44.

LEITÃO, Bárbara Júlia Menezello. A relação entre as bibliotecas públicas, bibliotecários e a censura na Era Vargas e Regime Militar: uma reflexão. Tese (doutorado em Ciência da Comunicação) - Universidade de São Paulo, São Paulo, 2010.

LEMOS, Antônio Agenor Briquet de. Bibliotecas. In: CAMPELLO, Bernadete Santos; CALDEIRA, Paulo da Terra Caldeira (org.). Introdução às fontes de informação. 2. ed. Belo Horizonte:

Autêntica, 2008.

LOURENÇO FILHO, M. B. O ensino e a biblioteca. Rio de Janeiro: Imprensa Nacional, 1946. 1a Conferência da Série "A educação e a biblioteca", pronunciada na Biblioteca do DASP, em 05/07/1944.

MACHADO, Maria Cristina Gomes. O decreto de Leôncio de Carvalho e os Pareceres de Rui Barbosa em debate: a criação da escola para o povo no Brasil no século XIX. In: STEPHANOU, Maria; BASTOS, Maria Helena Camara. Histórias e memórias da educação no Brasil. Petrópolis, RJ: Vozes, v.2, p.91-103, 2011.

MARTINS, Marcus Vinicius Rodrigues. A biblioteca escolar no processo de escolarização da leitura no contexto do movimento Escola Nova: 1920-1940. 2013. Dissertação (Mestrado em Ciência da Informação) - Universidade Federal de Minas Gerais, Belo Horizonte, 2013.

MENEZES, Ebenezer Takuno de; SANTOS, Thais Helena dos. Verbete Manifesto dos Pioneiros da Educação Nova. In: DICIONÁRIO INTERATIVO DA EDUCAÇÃO BRASILEIRA - Educabrasil. São Paulo: Midiamix, 2001. Disponível em: http://www.educabrasil.com.br/manifesto-dospioneiros-da-educacao-nova/ Acesso em: 3 de abr. 2019. 
NUNES, C. Historiografia comparada da escola nova: algumas questões. Rev. Fac. Educ., São Paulo, v.24, n.1, p.105-125, jan. 1998. Disponível em:

https://www.scielo.br/scielo.php?script=sci_arttext\&pid=S0102-25551998000100008 Acesso em: 20 de set. 2020.

OLIVEIRA, Debora S. de. Biblioteca escolar e regime de informação: a lei n.12.244/2010 e a produção intelectual de pesquisadores e bibliotecários. 2019. Dissertação (Mestrado em Ciência da Informação) - Universidade Federal Fluminense, Niterói, 2019.

RIBEIRO, Maria Luisa Santos. História da educação brasileira: a organização escolar. Campinas, São Paulo: Autores Associados, 1998.

ROMANELLI, Otaíza de Oliveira. História da Educação no Brasil. Petrópolis, RJ: Vozes, 2012.

ROTHEN, José Carlos. O Instituto Nacional de Estudos Pedagógicos: uma leitura da RBEP. R. Bras. Est. Pedag., Brasília, v.86, n.212, p.189-224, jan./abr. 2005.

SCHUELER, Alessandra Frota Martinez de; MAGALDI, Ana Maria Bandeira de Mello. Educação escolar na primeira república: memória, história e perspectivas de pesquisa. Tempo [online]. Niterói, vol.13, n.26, pp.32-55, 2009.

SOUZA. Elisabete G. de. Relação trabalho-educação e questão social no Brasil: uma leitura do pensamento pedagógico da Confederação Nacional da Indústria - CNI (1930-2000). 2012. Tese (doutorado) - Universidade Estadual de Campinas, Faculdade de Educação.

TANURI, Leonor Maria. História da formação de professores. Revista Brasileira de Educação, Rio de Janeiro, n.14, p.61-88, maio/ago. 2000.

TAVARES, Mariana Rodrigues. Editando a nação e escrevendo sua história: o Instituto Nacional do Livro e as disputas editoriais entre 1937-1991. Aedos, Porto Alegre, n.15, v.6, p.164-180, jul./dez. 2014.

TEIXEIRA, Anísio. O humanismo técnico. Boletim CBAI. Rio de Janeiro, v.8, n.2, p.1186-1187, 1954. VÁLIO, Else Benetti Marques. Biblioteca escolar: uma visão histórica. Transinformação, Campinas, SP, v.2, n.1, p.15-24, jan./abr.1990. 